\title{
Alternative Reducing Agents in Metallurgical Processes: Gasification of Shredder Residue Material
}

\author{
Samira Lotfian $^{1} \cdot$ Hesham Ahmed ${ }^{1,2} \cdot$ Abdel-Hady A. El-Geassy $^{2} \cdot$ Caisa Samuelsson $^{1}$
}

Published online: 10 October 2016

(C) The Author(s) 2016. This article is published with open access at Springerlink.com

\begin{abstract}
Shredder residue material (SRM) contains plastic material, which has a potential to replace metallurgical coal for reduction during bath-smelting processes. Among the important parameters affecting its implementation are the gasification and the reactivity of char. Therefore, prior to considering its application in metallurgical processes, the gasification characteristics of the produced char need to be studied. Although the char produced from SRM contains lower fixed carbon compared with coal char, it has a porous structure and high surface area, which makes it highly reactive during gasification experiments. In addition to physiochemical properties, the catalytic effect of ash content of SRM char is attributed to its higher reactivity and lower activation energy compared with coal char. Furthermore, the effect of devolatilization heating rate on the gasification characteristics of produced char is investigated. It was found that the devolatilization heating rate during char production has a considerable effect on morphological
\end{abstract}

The contributing editor for this article was Veena Sahajwalla.

Samira Lotfian

samira.lotfian@1tu.se

Hesham Ahmed

hesham.ahmed@ltu.se

Abdel-Hady A. El-Geassy

caisa.samuelsson@1tu.se

Caisa Samuelsson

elgeassy@yahoo.com

1 MiMer, Luleå University of Technology, 97187 Luleå, Sweden

2 Department of Minerals Technology and Processing, Central Metallurgical Research and Development Institute (CMRDI), P.O. Box 87, Helwan, Cairo, Egypt properties of the char product. Moreover, the gasification reactivity of char produced at a fast devolatilization heating rate was the highest, due to the less crystalline structure of the produced char.

Keywords Shredder residue material - Char . Gasification · Reducing agent $\cdot$ Bath smelting

\section{List of Symbols}

$X \quad$ Char conversion

$w_{0} \quad$ Initial weight of char

$w_{\infty} \quad$ Saturation value of the weight-loss curve

$w(t) \quad$ Sample weight at a time $t$

$r \quad$ Gasification rate of the isothermal gasification

$\rho \quad$ Gasification rate of the nonisothermal gasification

$E_{\mathrm{a}} \quad$ Activation energy

A Preexponential factor

$R_{\mathrm{S}} \quad$ Reactivity index

$\tau_{50} \quad$ Time (in minute) required to reach the carbon conversion of $50 \%$

$w_{\mathrm{C}} \quad$ Weight of carbon in the sample remaining unreacted at the time $t$

\section{Introduction}

Shredder residue material (SRM) is the residue from shredding of end-of-life equipment, after removal of the main metallic content. SRM is an inhomogeneous material consisting of metals and ceramics, in addition to organic materials such as different types of plastics [1]. The amount of SRM is ever increasing, and the material is currently mainly landfilled or incinerated. The proper management of this complex residue material is a growing concern. Although SRM does not contain enough metals to 
be economically feasible as a secondary raw material in metallurgical processes, it contains considerable quantities of plastic materials. Plastic materials contain carbon and hydrogen, which makes them a possible alternative reducing agent [2]. Injection of plastic material in blast furnace has been reported in the literature and implemented in several industrial plants [2-4]. One limitation in using plastic-containing residue material for iron making is the content of metals such as zinc and copper which are not desirable in iron-making processes [5]. Therefore, utilizing plastic-containing residue material in nonferrous processes is more feasible and has no detrimental effect on final product quality. Therefore, SRM has the potential to replace part of the fossil coal used for reduction of oxides in bath-smelting processes.

Thermal decomposition of coal and its interaction with the melt in bath-smelting processes are studied [6]. In these processes, pulverized coal is injected alongside air into molten slag. The coal particles that are entrained in the melt release moisture and devolatilize instantaneously, forming a gaseous envelop, which surrounds the remaining char [7]. At the interface of the gaseous envelop with the molten slag, oxides are reduced by $\mathrm{CO}$ and $\mathrm{H}_{2}$ [8]. The $\mathrm{CO}_{2}$ produced from the reduction reaction diffuses inside the bubble and reacts with carbon in char, generating $\mathrm{CO}$ via the Boudouard reaction with carbon in char, as illustrated in Fig. 1. The hydrogen content of volatiles also participates in the reduction through an equivalent reaction to produce $\mathrm{H}_{2} \mathrm{O}$ [7]. Carbon in char can react with $\mathrm{CO}_{2}$, $\mathrm{H}_{2} \mathrm{O}$, or $\mathrm{O}_{2}$, where reaction of $\mathrm{O}_{2}$ is very fast and reaction with $\mathrm{H}_{2} \mathrm{O}$ is insignificant. Therefore, the rate of $\mathrm{CO}_{2}$ gasification of chars is the lowest and the most significant, and consequently, it is considered as the rate-determining step during thermal decomposition [9].

Gasification of plastic materials has been reported in the literature $[10,11]$; however, in these studies, the material is heated up under $\mathrm{CO}_{2}$ atmosphere. In this way, simultaneous devolatilization and gasification as well as volatile interaction with $\mathrm{CO}_{2}$ will occur. Consequently, char gasification characteristics are very difficult to determine. Since in metallurgical applications, the reducing agent could participate in reactions through volatiles or fixed carbon in char, it is important to study these two stages separately. In addition, in the literature, there is a lack of study of a complex material such as SRM, which is a mixture of plastics alongside inorganic materials. Most studies deal with the gasification of char produced from individual plastics $[9,12,13]$. As an example, Wu et al. [9] studied the effect of physiochemical properties and gasification temperature on the conversion rate of char derived from three common plastics in electronic scrap at $873 \mathrm{~K}$. Results showed that as the gasification temperature increases, the conversion time decreases, and the gasification reactivity was the highest for char with the highest surface area and the lowest carbon crystalline degree.

In the present investigation, the aim is to study and compare the gasification of SRM as an alternative reducing agent with the current reducing agent, coal. Gasification reaction and char reactivity are influenced not only by the nature of material but also by the conditions during the devolatilization stage. One of the devolatilization parameters is the heating rate, which greatly differs between lab scale and real operation conditions. Therefore, the effect of devolatilization heating rate on the produced char is studied.

\section{Materials and Methods}

SRM and coal samples as reference material for comparison purposes were used to produce char samples. Ultimate analysis based on standard ${ }^{1}$ was carried out for all samples by the certified laboratory ALS Scandinavia AB, Sweden. Proximate analyses of original samples and char samples were performed using thermogravimetric analyzer (TGA, Netzsch Thermal Analyzer STA 409); the results are presented in Table 1. Proximate analysis involves heating the sample in Argon (99.999 \% purity) at a heating rate of $10 \mathrm{~K} / \mathrm{min}$ from room temperature to $383 \mathrm{~K}$ with a holding time of $10 \mathrm{~min}$ to remove moisture. In the next step, the samples were heated up to $1223 \mathrm{~K}$. The weight loss in this stage is associated with the volatile content. After the sample reached a constant weight loss (i.e., devolatilization is completed), argon was replaced by air to oxidize the residual char; the observed weight loss corresponds to the fixed carbon content. During this stage, the metals in SRM can also be oxidized affecting weight change. The remaining residue represents the ash content of the material [14].

\section{Char Preparation}

Pulverized coal with particle size of less than $38 \mu \mathrm{m}$ (as received) and SRM with particle size of less than $0.5 \mathrm{~mm}$, with average weight of $5 \mathrm{~g}$ were devolatilized in a vertical tube furnace. A schematic representation of the furnace is shown in Fig. 2. The furnace consisted of a kanthal wirewound tube furnace (length: $100 \mathrm{~cm}$, diameter: $12.5 \mathrm{~cm}$ ). A stainless steel tube (length: $135 \mathrm{~cm}$, outer diameter: $6.5 \mathrm{~cm}$ ) closed at the bottom end was placed inside the

\footnotetext{
${ }^{1}$ Ultimate analysis standard for coal: CHN ASTM D5373, Sulfur SS 187,177 , Oxygen calculated, Ultimate analysis standard for SRM: CHN SS-EN 15104:2011, Oxygen calculated.
} 
Fig. 1 Representation of role of coal as a reducing agent in slag fuming process, and parameters affecting the gasification reaction (adopted from [7])
Table 1 Ultimate and proximate analyses of original SRM and coal samples

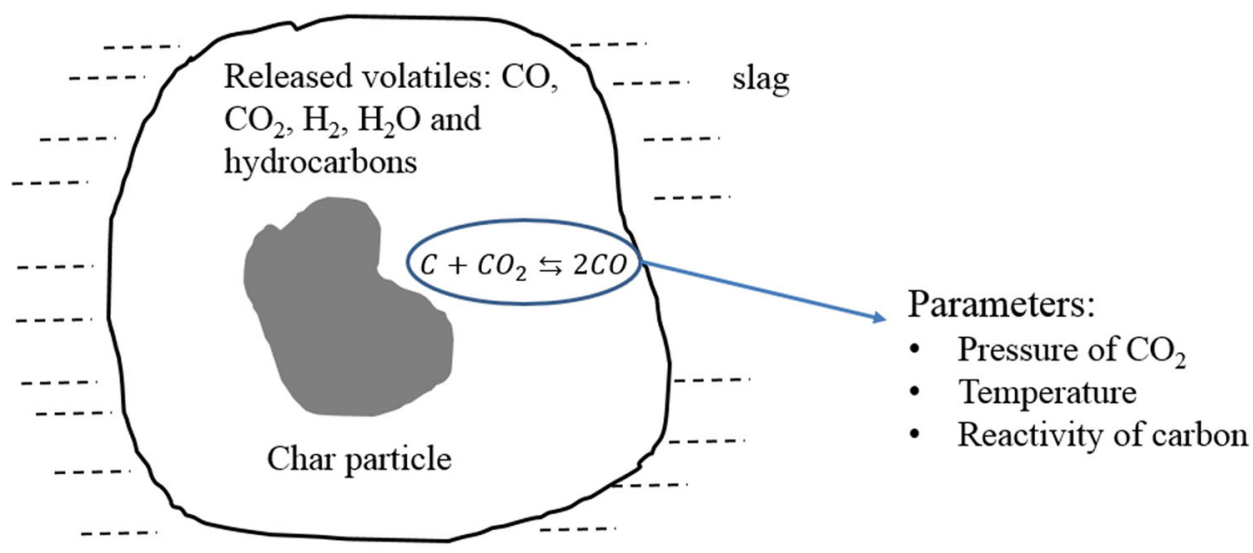

\begin{tabular}{|c|c|c|c|c|c|c|}
\hline & $\mathrm{H}(\mathrm{wt} \%)$ & $\mathrm{O}(\mathrm{wt} \%)$ & \multicolumn{2}{|c|}{$\mathrm{N}(\mathrm{wt} \%)$} & $\mathrm{S}(\mathrm{wt} \%)$ & $\mathrm{C}(\mathrm{wt} \%)$ \\
\hline \multicolumn{7}{|l|}{ Ultimate analysis by standard } \\
\hline Coal & 4.8 & 5.2 & \multicolumn{2}{|c|}{1.3} & 0.3 & 84.0 \\
\hline Shredder residue material & 6.1 & 12.0 & \multicolumn{2}{|c|}{1.8} & 0.08 & 56.9 \\
\hline & Moisture (wt $\%)$ & \multicolumn{2}{|c|}{ Volatile (wt $\%)$} & \multicolumn{2}{|c|}{ Fixed carbon $(\mathrm{wt} \%)$} & Ash $(\mathrm{wt} \%)$ \\
\hline \multicolumn{7}{|c|}{ Proximate analysis by thermogravimetric analyzer } \\
\hline Coal & $0.4 \pm 0.3$ & $22.7 \pm$ & \multicolumn{3}{|c|}{$66.7 \pm 1.6$} & $9.2 \pm 2.4$ \\
\hline Shredder residue material & $0.6 \pm 0.3$ & $66.9 \pm$ & \multicolumn{3}{|c|}{$9.3 \pm 1.9$} & $23.2 \pm 6.3$ \\
\hline
\end{tabular}

furnace. Nitrogen (99.996\% purity) at flow rate of $10 \mathrm{l} /$ min enters from the bottom passing through alumina beads to be heated up before it reaches the evenly heated zone. Nitrogen and volatiles released leave the furnace from the outlet at the top. Weight loss was continuously monitored with a balance at the top of the furnace. A K-type thermocouple is positioned at the evenly heated zone of the furnace to measure the furnace temperature. The sample is introduced close to the thermocouple, in the alumina crucible.

\section{Char Samples Produced at Slow and Medium Devolatilization Heating Rates}

The sample was placed in an alumina crucible (height of $63 \mathrm{~mm}$ and thickness of $0.7 \mathrm{~mm}$ ) and introduced to the furnace, suspended from the balance. Initially, $\mathrm{N}_{2}$ was introduced to the furnace for $15 \mathrm{~min}$ to ensure inert atmosphere, then the sample was heated up to $1173 \mathrm{~K}$ at a heating rate of $2 \mathrm{~K} / \mathrm{min}$ (slow devolatilization). Another sample was heated up at an average heating rate of $8 \mathrm{~K} / \mathrm{min}$ (medium devolatilization). Once the sample reached the desired temperature, it was removed from the heated zone and placed in the water cooled zone, where the char sample was cooled to room temperature in $\mathrm{N}_{2}$ atmosphere.
Char Samples Produced at Fast Devolatilization Heating Rate

The furnace was heated to $1173 \mathrm{~K}$, and $\mathrm{N}_{2}$ at a flow rate of $10 \mathrm{l} / \mathrm{min}$ was introduced and maintained for $15 \mathrm{~min}$. The sample placed in the alumina crucible was then introduced to the heated zone of the furnace and held until the weight loss stabilized. To estimate the heating rate during fast devolatilization and ensure a uniform heating of the sample, two thermocouples were inserted: one inside the sample, and one next to the alumina crucible, and it was shown that the temperature rose to $1173 \mathrm{~K}$ in $5 \mathrm{~min}$, i.e., the average heating rate is $180 \mathrm{~K} / \mathrm{min}$. The temperature drop in the water-cooled zone was also monitored using the thermocouple inside the sample. It showed that the temperature decreased from $1173 \mathrm{~K}$ to about $333 \mathrm{~K}$, in $10 \mathrm{~min}$. This cooling rate is valid during slow and medium devolatilizations as well. The heating cycles for all three char samples are presented in Fig. 3.

\section{Char Characterization}

Proximate analysis of char samples was determined using thermogravimetric analyzer, with the same procedure as for the original samples. Porosity and pore size distribution of 


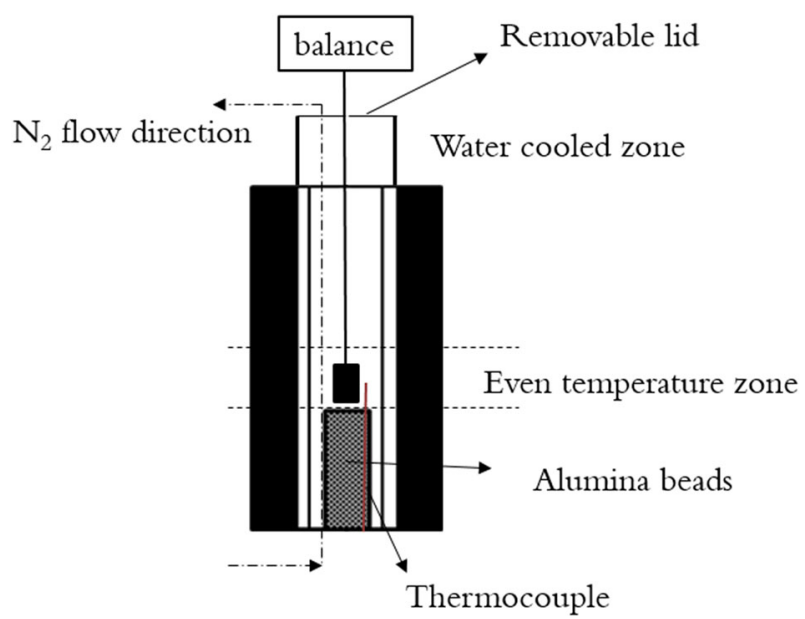

Fig. 2 Schematic of tube furnace

char samples were measured using a mercury porosimeter (Pore sizer 9320, micrometrics, USA). Mercury porosimetry is based on the gradual injection of liquid mercury into an evacuated pore at different applied pressures [15]. The surface area of char samples was measured using Micromeritics' flowsorb II 2300 and calculated by applying the Brunauer-Emmett-Teller (BET) equation to the adsorption/desorption isotherm $\left(\mathrm{N}_{2}-\mathrm{He}, 77 \mathrm{~K}\right)$. Morphology of produced char samples was studied using Zeiss Gemin Merlin scanning electron microscopy (SEM). A PANalytical Empyrean X-ray diffractometer equipped with copper $K_{\alpha}$ radiation was used to record the X-ray diffraction spectra of SRM char samples. The chemical analysis of SRM ash was performed in Boliden's-Rönnskär laboratory. $\mathrm{Cr}, \mathrm{Al}$, and $\mathrm{Mg}$ contents of SRM ash were determined by atomic absorption spectroscopy (AAS), where the samples were prepared by dissolving in $\mathrm{Na}_{2} \mathrm{O}_{2}$. The other elements were measured by dissolving in $\mathrm{HCl}$ and $\mathrm{HNO}_{3}$ and analyzed using inductively coupled plasma (ICP). The chemical analysis of coal ash was measured by the certified laboratory ALS Scandinavia AB, Sweden. The sample was fussed with $\mathrm{LiBO}_{2}$ and dissolved in $\mathrm{HNO}_{3}$. Finally, the elements were measured by ICP.

\section{Gasification Experiment}

Initial gasification experiments were performed isothermally using TGA. Char samples were manually crushed and sieved to a particle size of less than $100 \mu \mathrm{m}$. For this particle size range, it has been reported that the chemical reaction controls the kinetic of reaction and the effect of reactant diffusion is negligible [16]. In order to further minimize the interference of mass and heat transfer on gasification reaction, an initial set of experiments was performed. The conditions were selected to ensure the easy escape of locally produced $\mathrm{CO}$ and easy access of $\mathrm{CO}_{2}$ to the reaction sites. Based on these experiments, sample weights of $10 \mathrm{mg}$ and $20 \mathrm{mg}$ were selected for coal and SRM char, respectively. The char samples produced at medium devolatilization heating rate were heated up to different temperatures 1073 $1473 \mathrm{~K}$ with an interval of $50 \mathrm{~K}$, under Argon (99.999\% purity) atmosphere at heating rate of $10{ }^{\circ} \mathrm{C} / \mathrm{min}$. Once the
Fig. 3 Heating cycles of char samples produced at slow, medium, and fast heating rates

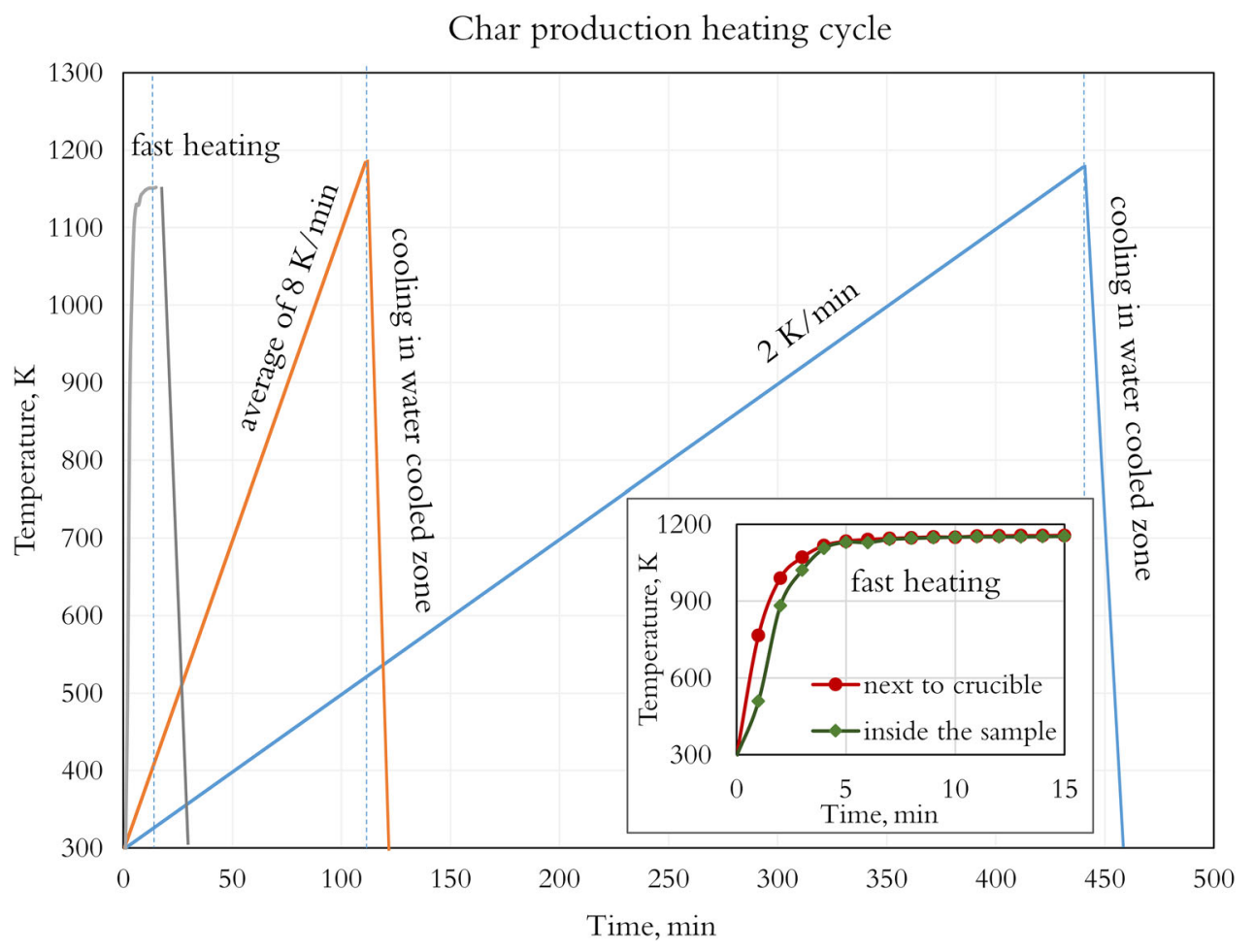


sample temperature stabilized at the desired temperature, the atmosphere was switched to $\mathrm{CO}_{2}(99.998 \%$ purity) at a flow of $200 \mathrm{ml} / \mathrm{min}$ and maintained for one hour. The char conversion is computed as a function of time [17]:

$X=\frac{w_{0}-w(t)}{w_{0}-w_{\infty}}$

Gasification rate is defined as differential of carbon conversion to gasification time:

$r=-\frac{1}{w_{0}-w_{\infty}} \frac{\mathrm{d} w}{\mathrm{~d} t}=\frac{\mathrm{d} X}{\mathrm{~d} t}$

Gasification of char is a heterogeneous gas-solid reaction; as $\mathrm{CO}_{2}$ is in excess, its partial pressure remains constant during the reaction. Therefore, the reaction rate constant is dependent on temperature and the kinetic parameters such as activation energy and preexponential factor can be calculated using the Arrhenius equation [18]:

$r=A \mathrm{e}^{-E_{\mathrm{a}} /(R T)}$

In general, to evaluate the overall gasification reactivity of char, reactivity index is used, which is defined by Eq. 4 [19]:

$R_{\mathrm{S}}=\frac{0.5}{\tau_{50}}$

Furthermore, to study the effect of devolatilization heating rate on gasification of char samples, the slow and fast devolatilized char were tested under nonisothermal condition, which has the advantage of studying the reaction in one experiment [20]. The kinetic parameters were calculated based on the assumption that the nonisothermal heating cycle consists of an infinite number of discrete isothermal sections, which are a first order reaction. The previously mentioned Arrhenius equation can be applied to those isothermal sections, with the modification of considering the weight of remaining carbon in the sample for each isothermal section [21]. $10 \mathrm{mg}$ of char samples were heated up to $623 \mathrm{~K}$ under argon at a flow rate of $100 \mathrm{ml} / \mathrm{min}$ at a heating rate of $20 \mathrm{~K} / \mathrm{min}$. Afterward, the heating rate was changed to $2 \mathrm{~K} / \mathrm{min}$, while $\mathrm{CO}_{2}$ at a flow of $200 \mathrm{ml} / \mathrm{min}$ was introduced. The samples were heated up to $1173 \mathrm{~K}$. The kinetic parameters are calculated based on Eq. 5.

$\rho=\frac{1}{w_{\mathrm{C}}} \frac{\mathrm{d} w_{C}}{\mathrm{~d} t}=A \mathrm{e}^{-E / R T}$

\section{Results and Discussion}

\section{Characterization of Char Samples}

\section{Proximate Analysis}

The proximate analyses of char samples produced at different devolatilization heating rates are presented in
Table 2. Comparison of the proximate analyses of coal and SRM char shows that SRM contains lower fixed carbon compared to that of coal. Coal char contain up to $80 \%$ fixed carbon, while SRM char has $20 \%$ fixed carbon. The proximate analyses of both SRM and coal char samples do not significantly change at different devolatilization rates.

Higher amounts of volatiles are present in SRM char compared with coal char. Mass spectroscopy analysis during proximate analysis of char shows the evolution of $\mathrm{H}_{2}$ and $\mathrm{H}_{2} \mathrm{O}$, which implies incomplete reactions during char production. It is known that, at the final stage of devolatilization, $\mathrm{H}_{2}$ is produced by the recombination of aromatic compounds [22]. Release of $\mathrm{H}_{2}$ during proximate analysis of char suggests the continuation of these reactions. $\mathrm{H}_{2} \mathrm{O}$ is probably produced from reduction reaction of oxides in ash with produced hydrogen. Finally, SRM has higher content of ash compared with coal, due to its content of metals and ceramic materials. A summary of elemental analysis of ash for coal and SRM is presented in Tables 3 and 4.

SRM char contains a lower amount of fixed carbon than coal char, which is due to the fact that SRM consists of plastics, which are known to produce lower amounts of fixed carbon compared with coal. Crosslinking and cyclization reactions are the important reactions that determine the amount of char produced during plastic thermal decomposition. Thus, some plastics such as polyethylene are decomposed mainly by release of volatiles (98\%), generating a low amount of char, while a plastic like polyvinylchloride produce a higher amount of char [23].

\section{Pore Size Distribution and Surface Area of Char Samples}

The characteristics of char samples prepared at slow and medium heating rates are similar; therefore the characterization results from the slow devolatilized char are presented and compared with the fast devolatilized char. Figure $4 \mathrm{a}$ shows the variation between cumulative intrusion measurements of the intruded $\mathrm{Hg}$ in coal and coal char samples versus the corresponding pore diameter. Cumulative intrusion volume is a plot of the volume of mercury intruded into each gram of samples as a function of pore diameter [24].

Figure 4 shows that the cumulative intrusion in original the coal sample differs from the char samples produced at slow and fast devolatilization heating rates. In the original sample, the total intrusion volume of $\mathrm{Hg}$ gradually increases for a pore size range of 5-200 $\mu \mathrm{m}$, then sharply increases at pore diameters in the range of $0.3-3 \mu \mathrm{m}$, followed by a gradual increase. The cumulative intrusion volume observed for both the treated char samples were higher than the original coal sample in the pore size range 
Table 2 Proximate analyses of coal and SRM char

Table 3 The elemental composition of SRM ash

Table 4 The elemental composition of coal ash

\begin{tabular}{lllclc}
\hline & Heating rate $(\mathrm{K} / \mathrm{min})$ & Moisture $(\%)$ & Volatile $(\%)$ & Fixed carbon $(\%)$ & Ash $(\%)$ \\
\hline Coal char & Slow & 0.5 & 2.5 & 83.1 & 13.9 \\
& Medium & 0.6 & 2.7 & 84.8 & 12.1 \\
& Fast & 0.8 & 1.6 & 84.3 & 13.3 \\
SRM char & Slow & 1.6 & 10.2 & 23.6 & 64.0 \\
& Medium & 1.8 & 9.0 & 23.2 & 66.0 \\
& Fast & 2.3 & 9.4 & 23.1 & 65.2 \\
\hline
\end{tabular}

\begin{tabular}{lccllllllll}
\hline Element in ash & $\mathrm{Ca}$ & $\mathrm{Si}$ & $\mathrm{Cu}$ & $\mathrm{Al}$ & $\mathrm{Mg}$ & $\mathrm{Ti}$ & $\mathrm{Cr}$ & $\mathrm{Fe}$ & $\mathrm{Zn}$ & $\mathrm{Na}$ \\
\hline Wt\% & 12.9 & 12.6 & 11.5 & 11.0 & 2.6 & 2.3 & 0.6 & 0.4 & 0.3 & 0.1 \\
$\begin{array}{l}\text { Other elements } \\
\text { detected in ash in ppm level }\end{array}$ & & & $\mathrm{Pb}, \mathrm{Mo}, \mathrm{Se}, \mathrm{V}, \mathrm{Co}, \mathrm{Cd}, \mathrm{As}, \mathrm{Be}, \mathrm{Sb}, \mathrm{Ni}, \mathrm{Mn}$ & & & \\
\hline
\end{tabular}

\begin{tabular}{llllll}
\hline Elements in ash & $\mathrm{Si}$ & $\mathrm{Al}$ & $\mathrm{Ca}$ & $\mathrm{Fe}$ & $\mathrm{Mg}$ \\
\hline $\mathrm{Wt} \%$ & 0.5 & 0.2 & 0.5 & 0.5 & 0.2 \\
Other elements detected in ash in ppm level & $\mathrm{K}, \mathrm{Na}, \mathrm{P}, \mathrm{Mn}, \mathrm{Ti}, \mathrm{Ba}, \mathrm{be}, \mathrm{Cr}, \mathrm{Nb}, \mathrm{W}, \mathrm{Sc}, \mathrm{Sr}, \mathrm{Zr}$ \\
\hline
\end{tabular}

of 5-200 $\mu \mathrm{m}$, while in the pore diameters in the range of $0.3-3 \mu \mathrm{m}$, the original sample was higher than that in the coal char samples. The latter pore size range almost disappeared for char samples. The population of pore size in the size range of 5-200 $\mu \mathrm{m}$ increased in the order of, fast devolatilized char $>$ slow devolatilized char $>$ original sample. This indicates that at the higher devolatilization heating rate, a larger number of macropores is formed at the expense of smaller pores.

Figure $4 \mathrm{~b}$ shows the variation between the cumulative intrusion of $\mathrm{Hg}$ versus the pore diameter in the original SRM and the SRM char samples. There is a gradual increase in the total intruded volume of $\mathrm{Hg}$ for the pore size range of 5-200 $\mu \mathrm{m}$ for all samples; afterward, the slopes decrease slightly. The original sample shows an increase in the cumulative pore volume for the $0.03-0.001 \mu \mathrm{m}$, indicating the presence of micropores, which disappear in the char samples. The cumulative intrusion volume decreases with the increase in the devolatilization heating rate as compared with the original SRM sample. This indicates that, unlike the coal sample, at a slow devolatilization rate a larger number of pores are formed.

The effect of heating rate during the devolatilization step on the surface area of the corresponding produced coal and SRM char samples is shown in Table 5. For both SRM and coal char samples, the surface area is not significantly affected by the devolatilization heating rate; however, char samples produced at fast heating show a slight increase in surface area, compared to that produced at a slow devolatilization heating rate. This could be due to the slight sintering at slow and medium devolatilization. At any devolatilization heating rate, the surface area of the produced SRM char samples is higher than that of coal chars.

\section{Morphology of Char Samples}

The morphology of the char samples produced at fast and slow devolatilization heating rates was studied using scanning electron microscopy (SEM). Coal char produced by fast devolatilization (Fig. 5) shows a more porous structure compared with char produced at a slow heating rate. This is in agreement with the result of mercury porosimetry indicating higher population of macropores observed in char produced at a fast heating (Fig. 4a). A closer examination of the morphology shows that char produced at a slow devolatilization rate consists of individual particles in the size range of the original coal sample (Fig. 6). Comparison of the morphology of char produced at slow devolatilization in Fig. 5c and the original sample (Fig. 6) suggests that the sample sintered. The structure of char at fast devolatilization heating indicates melting and plastic deformation with ash particles appearing as bright spots. Original coal porosity decreases during devolatilization by either sintering of sample (slow heating rate) or melting of structure (fast heating rate).

The effect of devolatilization heating rate on the structure of coal char can be explained by the thermoplastic properties of coal. At a slow devolatilization heating rate, 
Fig. 4 Cumulative pore volumes for a original coal and coal chars, b original SRM and SRM char samples produced at slow and fast devolatilization heating rates
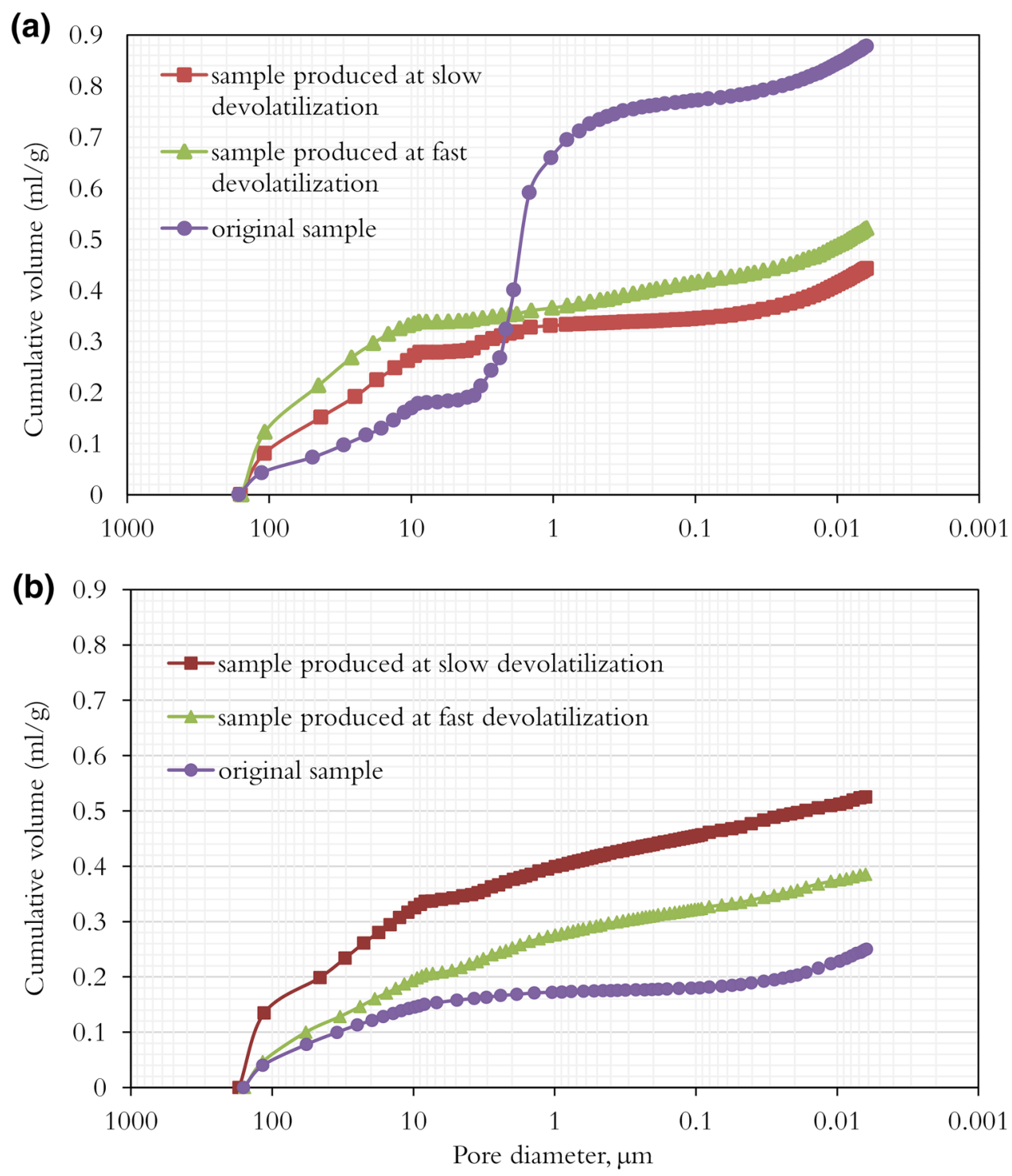

Table 5 Effect of devolatilization heating rate on BET Surface area $\left(\mathrm{m}^{2} / \mathrm{g}\right)$ of SRM char, after crushing to less than $100 \mu \mathrm{m}$

\begin{tabular}{llll}
\hline Sample & \multicolumn{3}{l}{ Devolatilization heating rate $(\mathrm{K} / \mathrm{min})$} \\
\cline { 2 - 4 } & Slow & Medium & Fast \\
\hline SRM char & 17.5 & 16.9 & 18.3 \\
Coal char & 13.2 & 13.6 & 15.5 \\
\hline
\end{tabular}

coal does not show much fluidity, while at a fast devolatilization heating rate, the fluidity is more pronounced. At a high heating rate, coal becomes soft, and pore opening is blocked by the onset of plastic stages. At this stage, volatiles are trapped in the coal and diffuse to form bubbles rather than exiting the coal directly. When a bubble reaches the surface, it releases the volatile matter
[25]. Hence, the coal char produced at a fast devolatilization rate, as shown in Fig. 5d, presents a molten structure and contains larger macropores, while the char produced at a slow devolatilization rate appears as sintered.

SEM images of the original SRM sample (Fig. 7a, b) show diversity in the morphology of this material. Differences in the colors of the observed phases in the backscattered image (Fig. 7b) suggest the presence of different phases. The effect of devolatilization heating rate on structure of char is less clear for SRM char compared with coal char, as, in both SRM char samples, the compact plastic structure is changed by the release of high amount of volatiles (Fig. 8a, b). The volatile that is released opens some new pores, and the particles consequently develop more macropores compared with the original sample, which is in agreement with the result from mercury porosimetry (Fig. 4b). Investigation of the structure of 

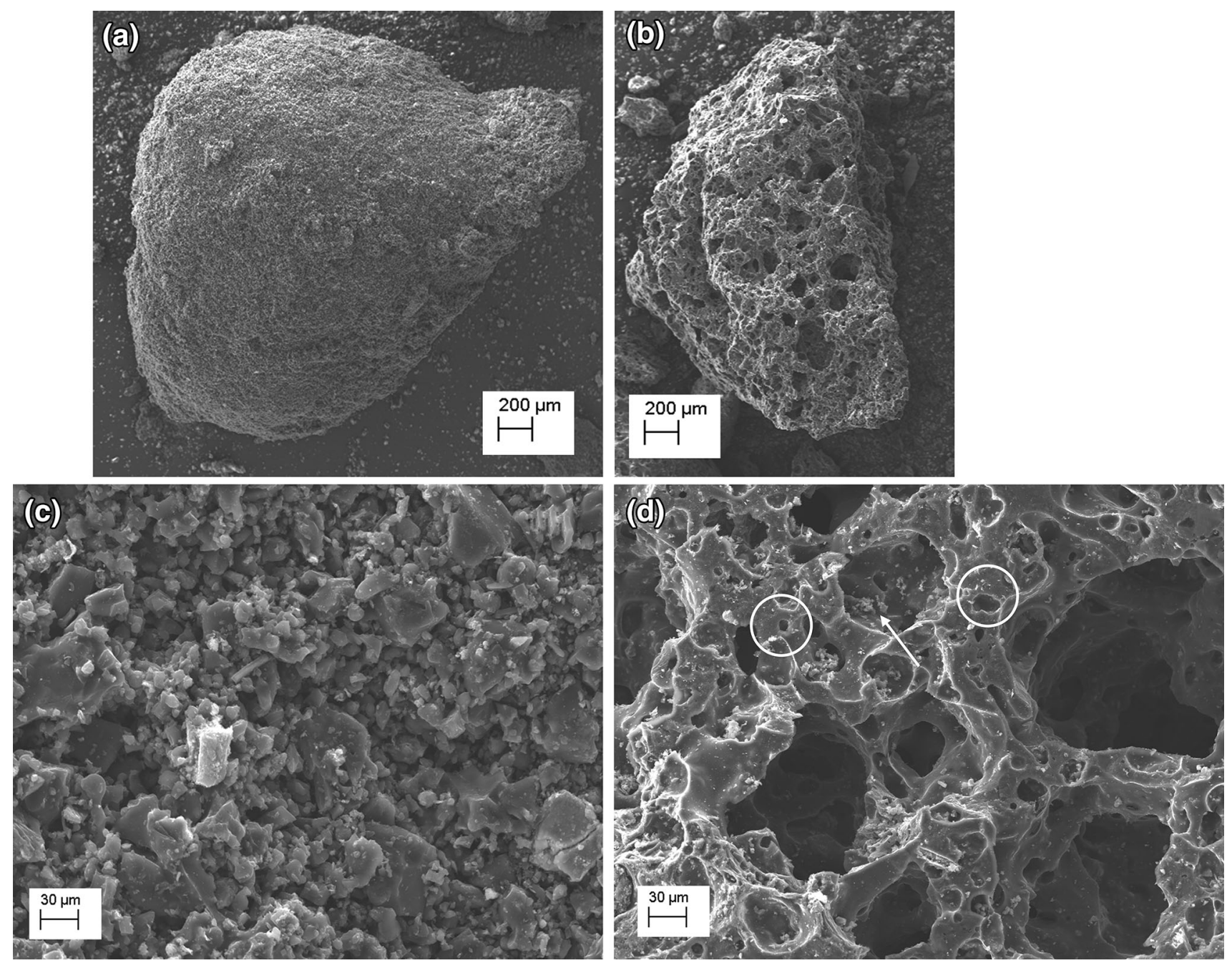

Fig. 5 Morphology of the coal char produced at a, c slow devolatilization; $\mathbf{b}, \mathbf{d}$ fast devolatilization, arrow in $\mathbf{d}$ shows the ash particles

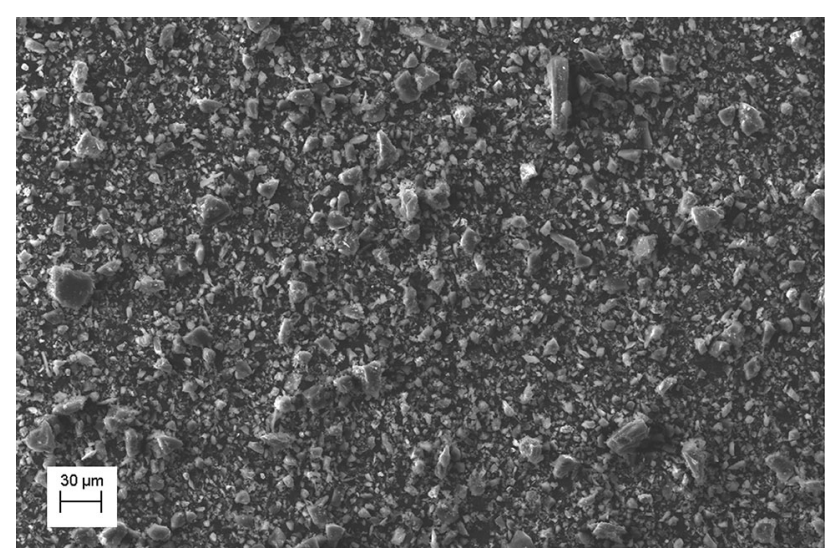

Fig. 6 Morphology of original coal sample

SRM char in Fig. 8 shows that wire-shaped particles still remain after devolatilization, while the rest of structure changed. This result suggests that the mentioned wire- shaped particles are inorganic parts, which are embedded in the plastic parts.

SRM char produced at fast devolatilization heating rate shows evidence of bubble formation during devolatilization. Figure 9a shows formation of a cenoshpere particle, which is probably formed by the internal pressure caused by release of volatiles inside the formed liquid film. A small hole is observed on top of the particle, which is probably caused by release of volatile. In the other char sample observed in Fig. 9b, the release of volatiles through the melt would lead to an eruption, as can be observed in the SEM image.

Other researchers have also reported formation of a liquid film on the outside layer of high volatiles containing materials [2]. Such a liquid film might be responsible for the formation of some closed pores in the char particles, which could be the reason for decrease in porosity of SRM char produced at a fast devolatilization rate, as observed in mercury porosimetry results. 

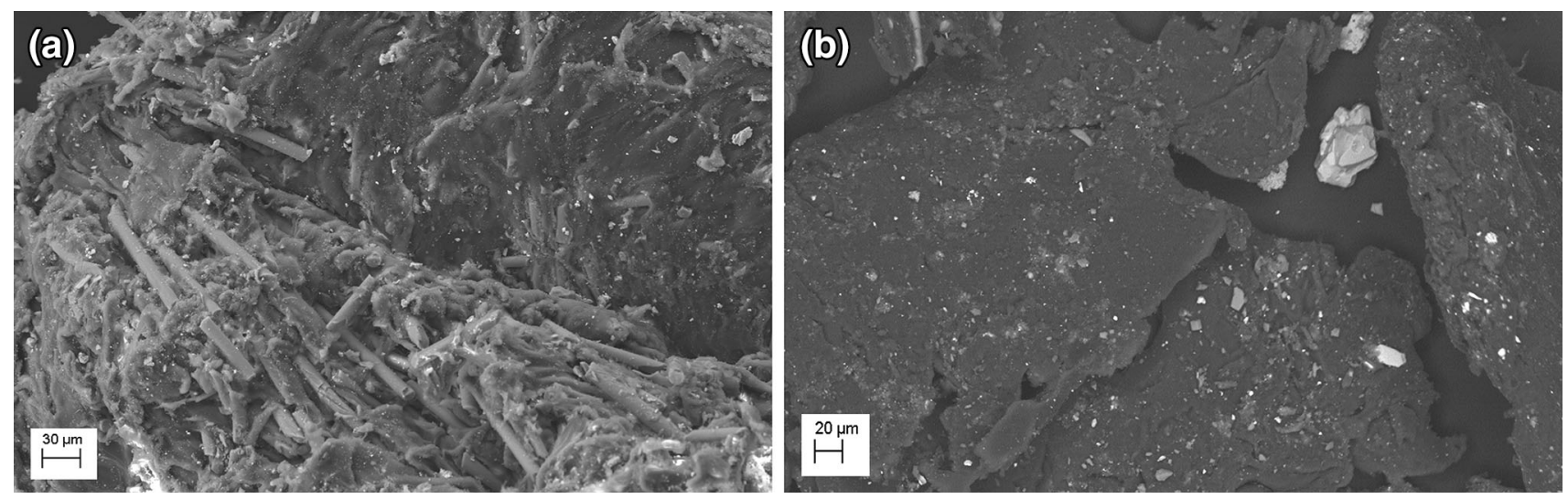

Fig. 7 Morphology of original SRM sample. a Secondary electron image. b Back-scattered scan
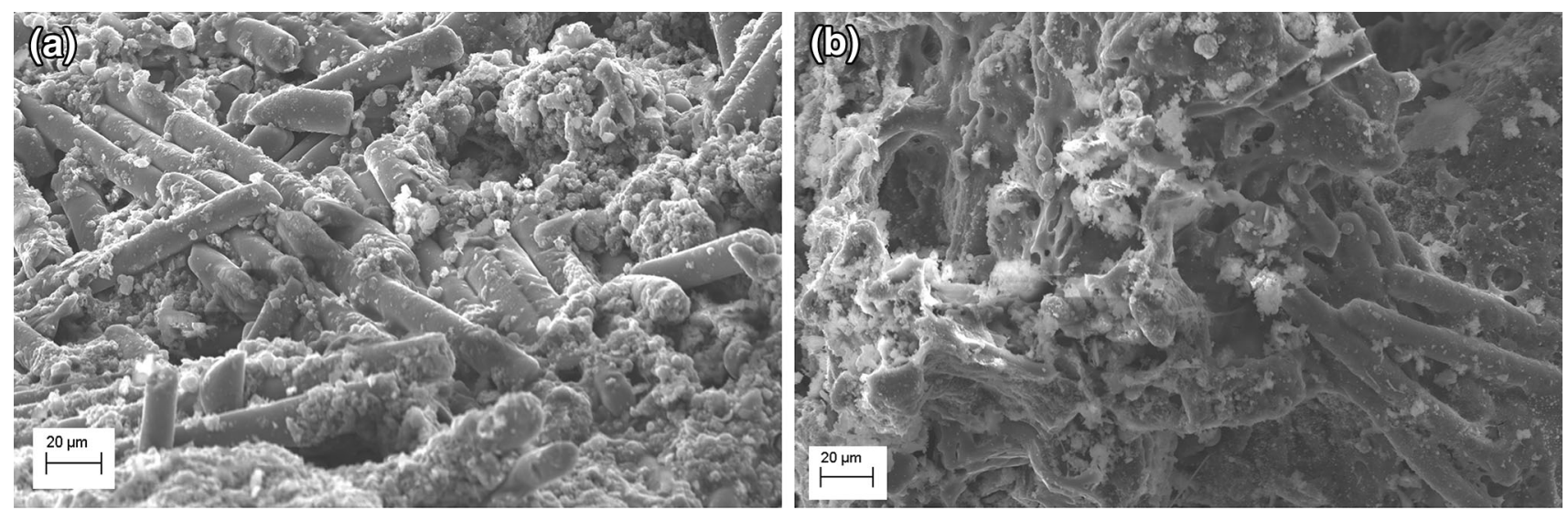

Fig. 8 Morphology of SRM chars. a produced at slow devolatilization; and b fast devolatilization rate
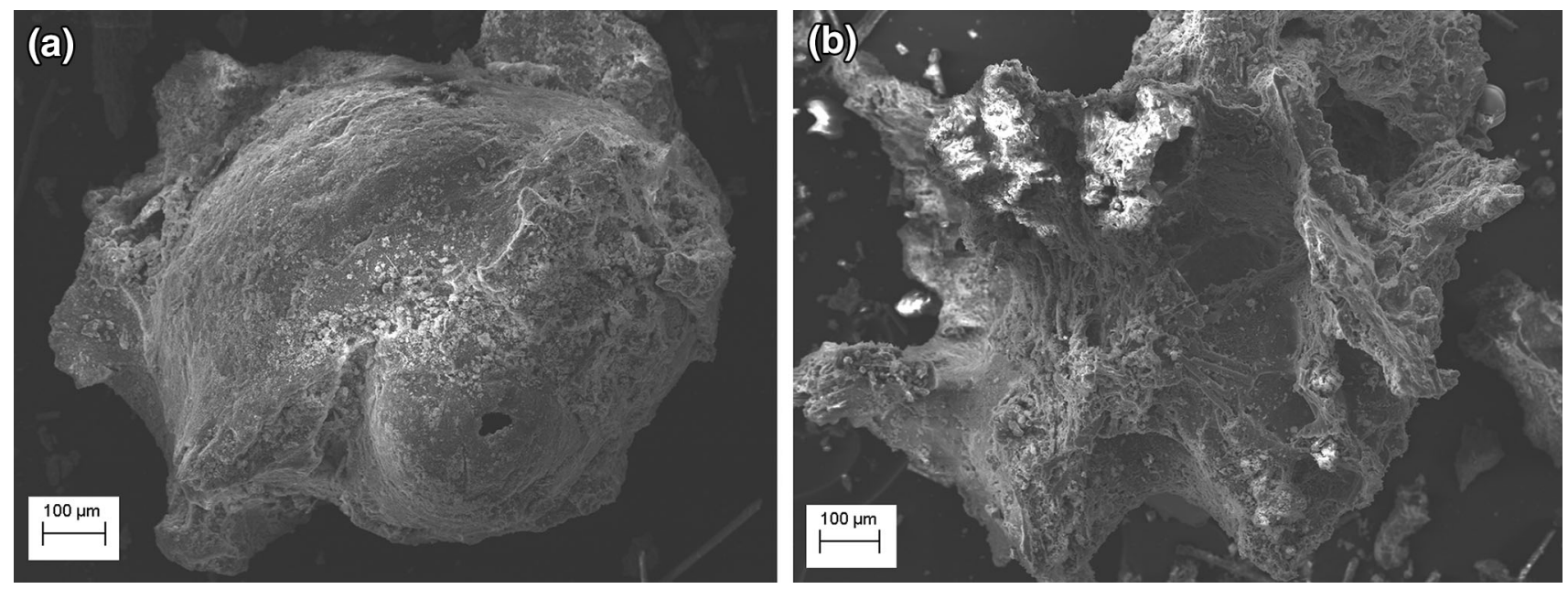

Fig. 9 SEM images of SRM char produced at fast devolatilization heating rate. a Formation of bubble. b Erupted bubble

For both SRM and coal char samples, the open and interconnected porous structure in the char sample produced during devolatilization offers an increased number of paths for the gas phase to access carbon sites. A summary of the phenomena occurring during SRM devolatilization is illustrated in Fig. 10. During devolatilization, irrespective of the heating rate, inorganic species do not show any significant changes, while organic 
species change completely. The structure of carbon formed by devolatilization of organic parts is affected by the thermal profile that SRM is exposed to.

\section{Gasification Experiments}

The effect of temperature on the carbon gasification of char produced at medium devolatilization heating rate was studied, the results are shown in Fig. 11. For both char samples, the time to complete carbon conversion decreased as the gasification temperature increased. At any given temperature and time, the conversion degree of SRM is always higher than that of coal char. Carbon conversion for coal char approaches completion only at temperatures higher than $1273 \mathrm{~K}$, while SRM char reaches complete conversion at temperatures higher than $1173 \mathrm{~K}$.

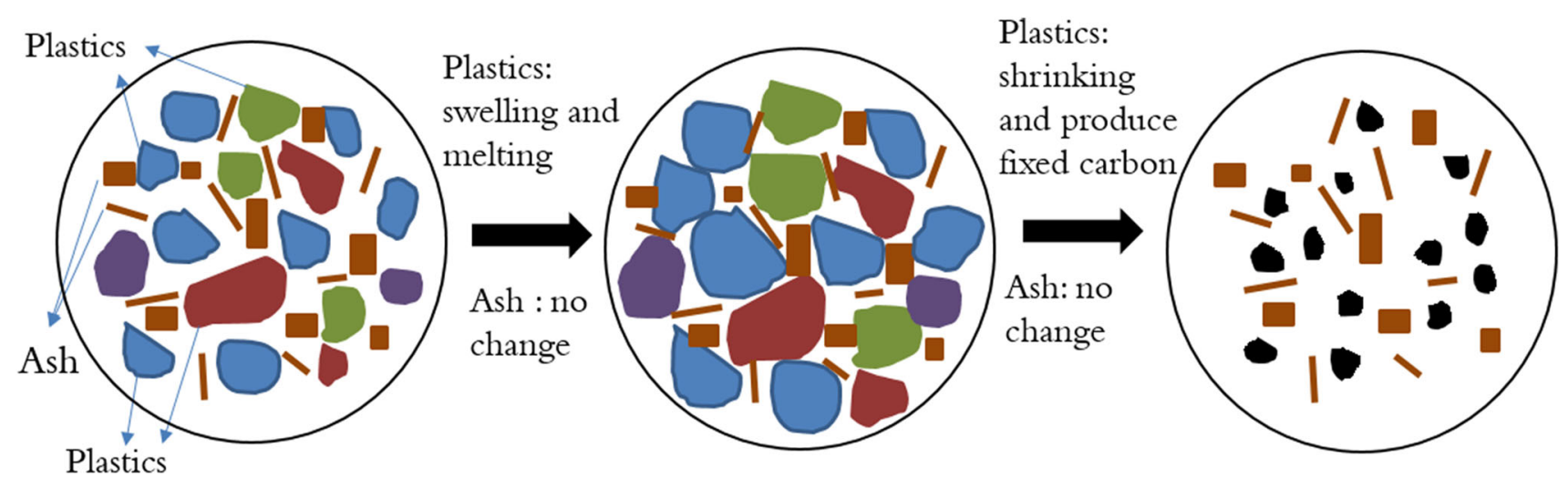

Fig. 10 Schematic illustration of behaviors of the mixture of different plastics as they are heated (inspired from [26])

Fig. 11 Carbon conversions at different temperatures for a coal char and b SRM char during isothermal gasification
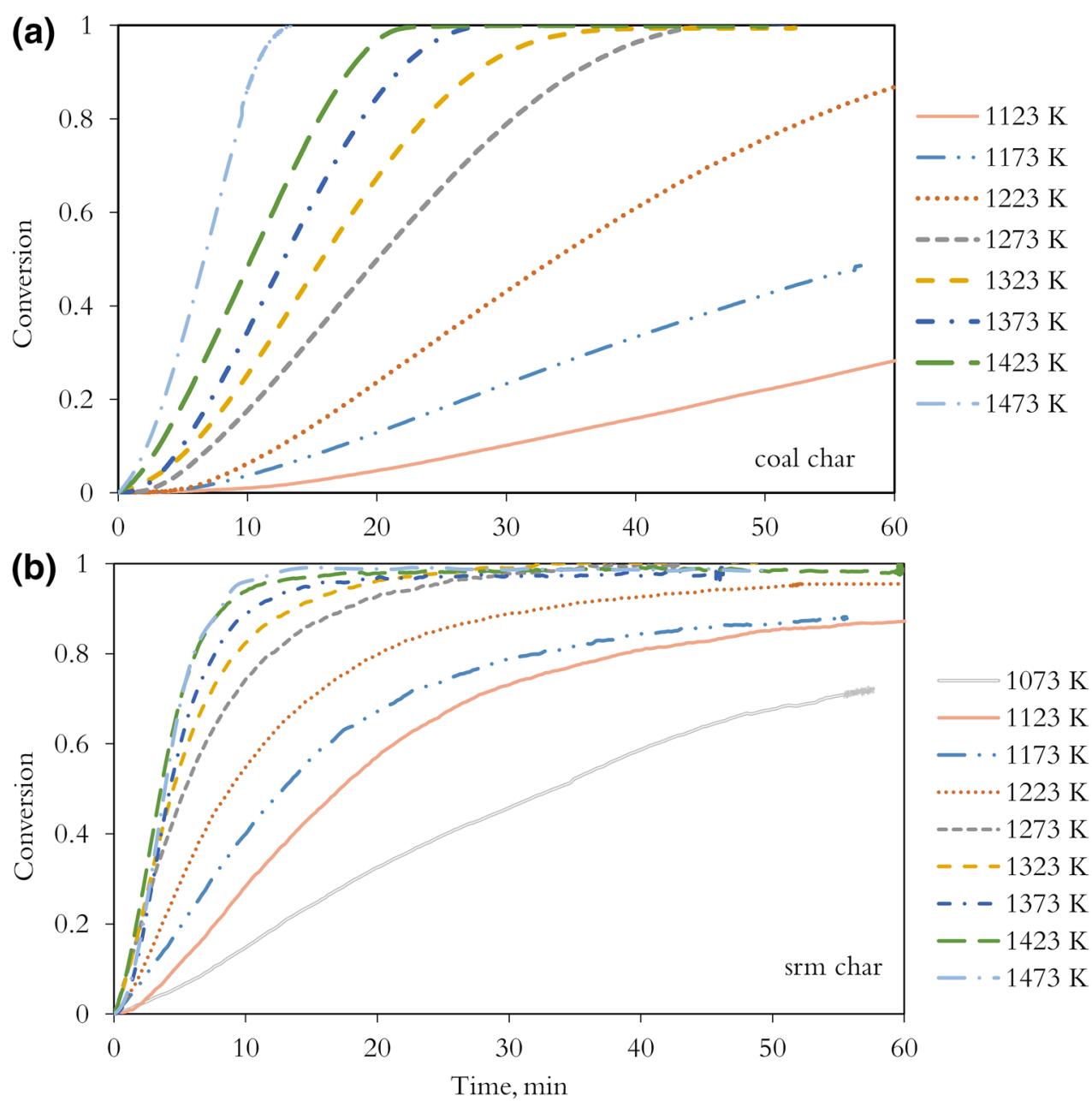
The reactivity index of char gasification is calculated based on Eq. 4, and the result is plotted in Fig. 12. The reactivity index of both char samples increased with the gasification temperature. At each temperature, SRM char shows higher reactivity than coal char.

The gasification kinetic of SRM and coal char during isothermal gasification at the initial stage of reaction is calculated using an Arrhenius plot, which is shown in Fig. 13. The calculated activation energy for coal char is $135.6 \mathrm{~kJ} / \mathrm{mol}$, while it is $116.4 \mathrm{~kJ} / \mathrm{mol}$ for SRM char. At temperatures higher than $1273 \mathrm{~K}$, the activation energy of coal char drops to $74.2 \mathrm{~kJ} / \mathrm{mol}$; similarly, the activation energy of SRM char drops to $53.8 \mathrm{~kJ} / \mathrm{mol}$ at $1273 \mathrm{~K}$. The decrease in the activation energies at these temperatures can be interpreted as a change in the rate-determining mechanism from chemical control to a mixed control, where the reaction occurs under the influence of pore diffusion.

The gasification rate of SRM char was higher than that of coal char; and the estimated activation energy for its gasification was lower than coal char. This difference could be due to different physical properties of material, such as surface area, morphology of char, and the pore distribution, which are known to play a vital role on gasification reactivity [9]. In addition, the ash content, especially alkali and alkaline earth metals (AAEM) and iron, are known to act as catalysts in the gasification reactions. Other inorganic substances such as silica, alumina and phosphates, on the other hand, lower the reactivity of char. Silica has been observed to reduce the reactivity by reacting with potassium to form silicate, blocking the catalytic effect of potassium. Alumina has also been shown to deactivate the catalytic activity of potassium. Potassium phosphate has been observed as inactive in the catalytic carbon gasification. The complicated effects of various ash components are often expressed by alkali index [19, 27]. The alkali index ( $A$ value) is calculated by Eq. 6. [28] The alkali

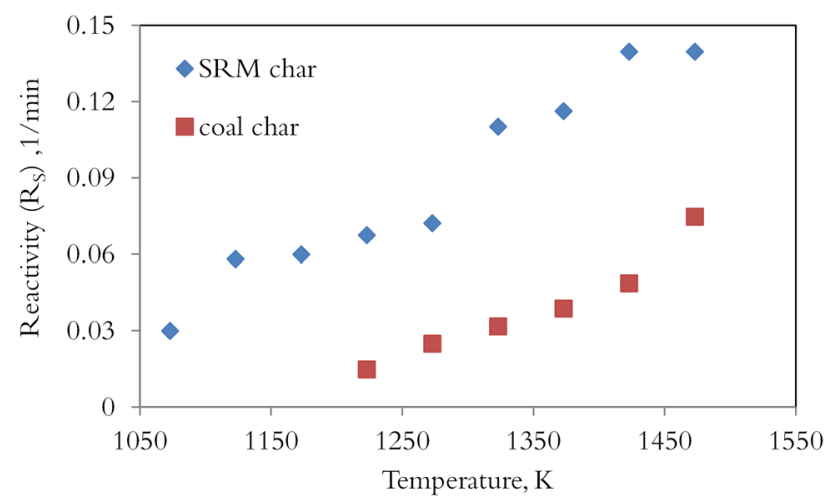

Fig. 12 Reactivity indices of coal and SRM char measured at different temperatures index calculated for coal char is 0.1 , while it is 0.4 for SRM char, indicating the higher catalytic effect of SRM char inorganic content, which leads to higher gasification rate and lower activation energy observed for SRM char. Considering utilizing this material in nonferrous metallurgy, after the gasification is completed, the inorganic compound in ash will dissolve in the slag. The process can be designed in such a way that the inorganic compound can be recycled.

$A=\mathrm{Ash} \times \frac{\mathrm{Fe}_{2} \mathrm{O}_{3}+\mathrm{Na}_{2} \mathrm{O}+\mathrm{K}_{2} \mathrm{O}+\mathrm{CaO}+\mathrm{MgO}}{\mathrm{Al}_{2} \mathrm{O}_{3}+\mathrm{SiO}_{2}}$

The effects of devolatilization heating rate on the gasification kinetics of char samples are compared using nonisothermal gasification tests. Figures 14 and 15 show the gasification rates versus reciprocals of temperature (Arrhenius plot) during nonisothermal gasification of SRM and coal char.

Table 6 shows the estimated kinetic parameters based on nonisothermal gasification in the temperature range for gasification. Gasification of SRM starts and finishes at lower temperatures, compared with coal char. The activation energies for both SRM char are lower than those of coal char, which is probably due to the mentioned catalytic effect of ash constituents.

The char samples produced at a slow heating rate show lower activation energy compared with char produced at
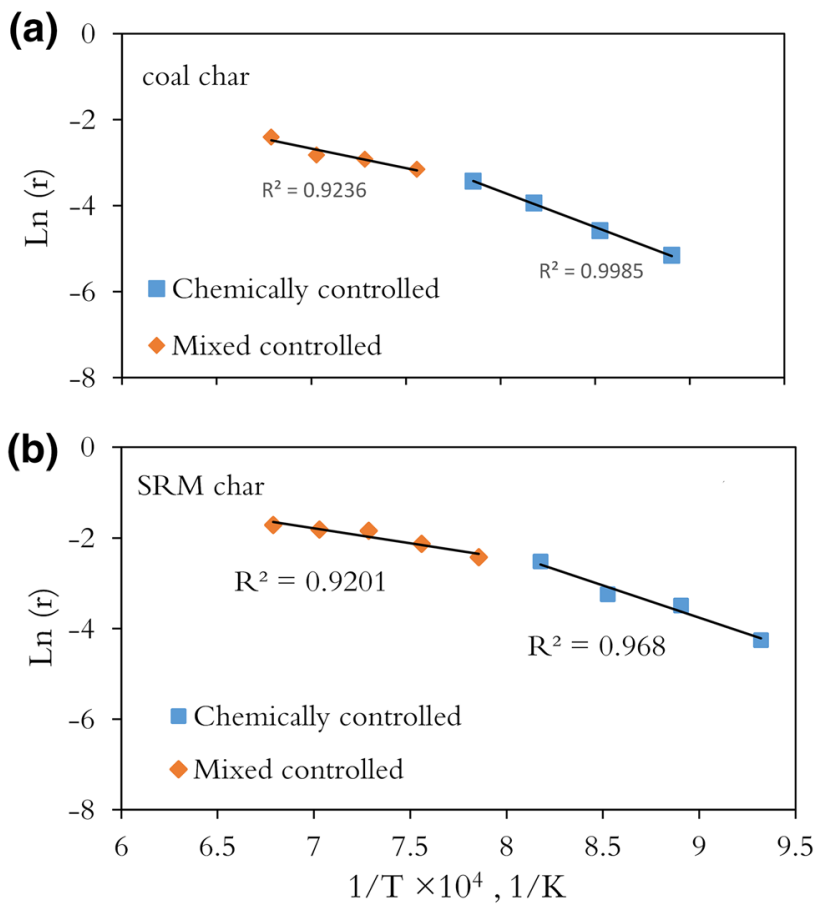

Fig. 13 Arrhenius plots of isothermal gasification at different temperatures. a Coal char. b SRM char 

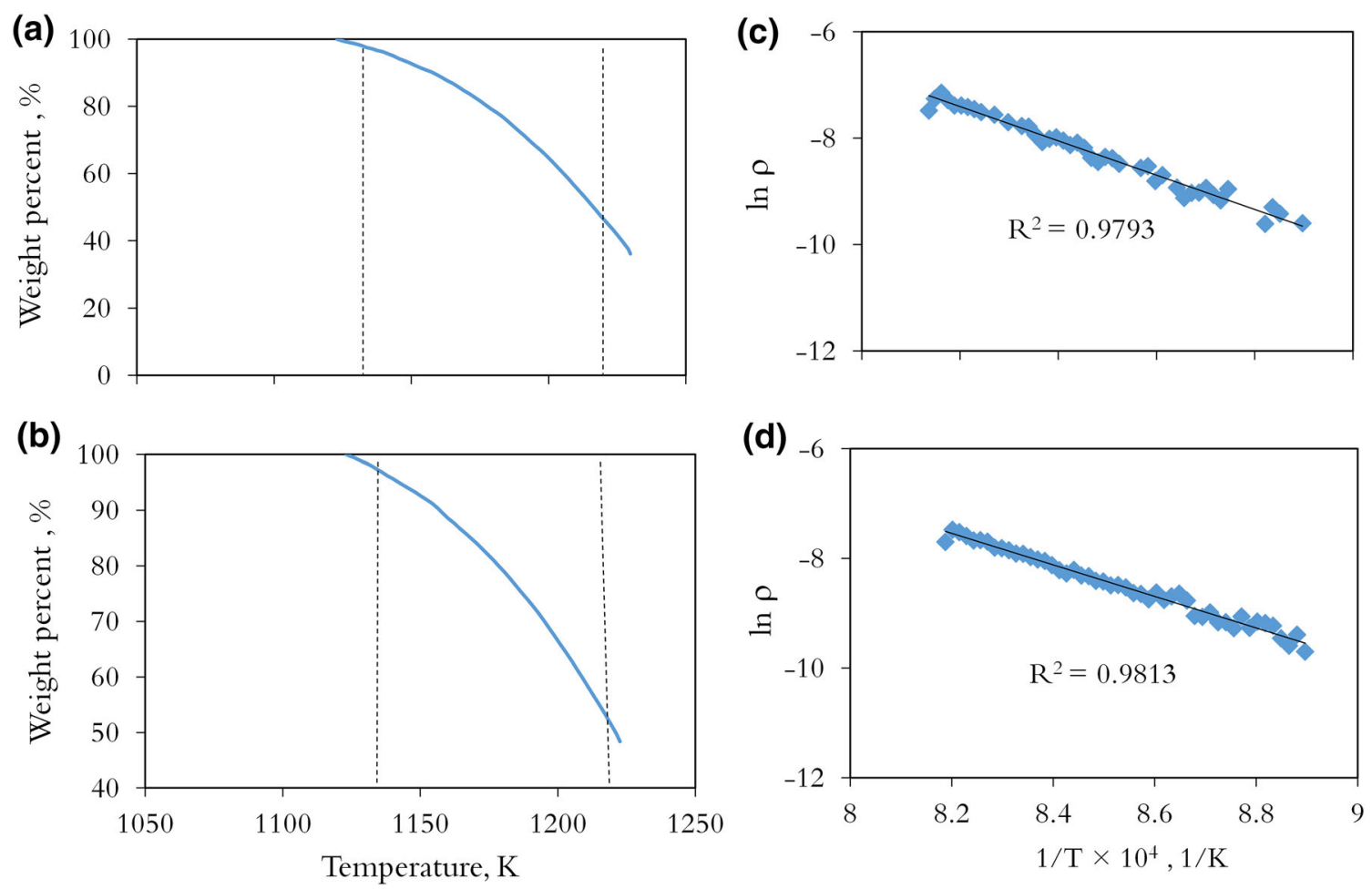

Fig. 14 The weight losses during nonisothermal gasification of char produced at a slow devolatilization, $\mathbf{b}$ fast devolatilization; and Arrhenius plots of $\mathbf{c}$ at slow, $\mathbf{d}$ fast devolatilization for coal char samples
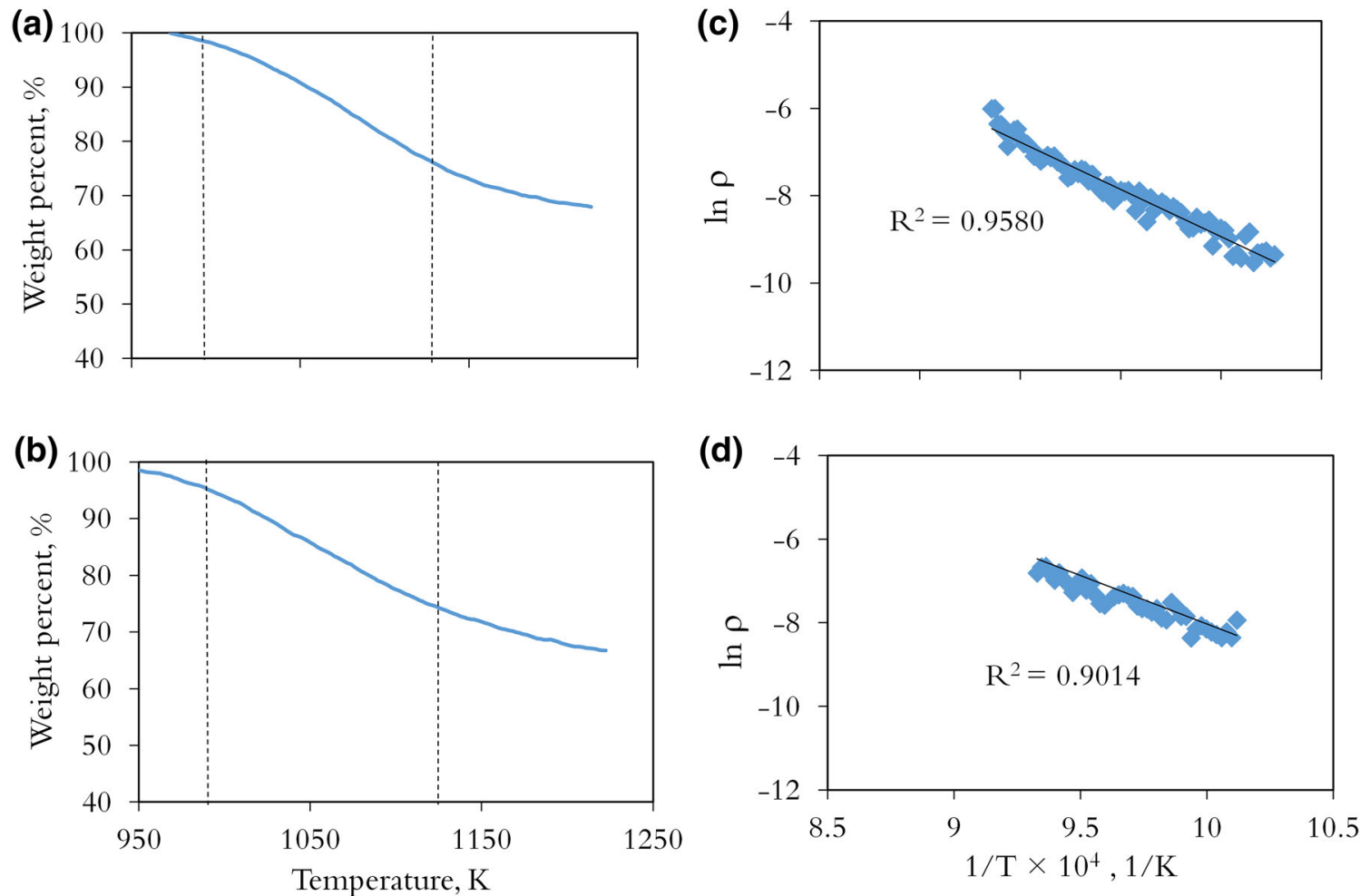

Fig. 15 The weight losses during nonisothermal gasification of char produced: a at slow devolatilization, b fast devolatilization; and Arrhenius plots: $\mathbf{c}$ at slow, $\mathbf{d}$ at fast devolatilizations for SRM char samples 
Table 6 Gasification temperatures and kinetic parameters of char samples produced at different heating rates, during nonisothermal gasification experiments

\begin{tabular}{llccc}
\hline & Devolatilization heating rate & Gasification temperature $(\mathrm{K})$ & Activation energy $(\mathrm{kJ} / \mathrm{mol})$ & Preexponential factor $(1 / \mathrm{s})$ \\
\hline Coal char & Slow & $1123-1223$ & 281 & $7.31 \times 10^{8}$ \\
& Fast & $1123-1223$ & 238 & $8.31 \times 10^{6}$ \\
\multirow{3}{*}{ SRM char } & Slow & $973-1123$ & 179 & $5.54 \times 10^{4}$ \\
& Fast & $973-1123$ & 166 & $5.41 \times 10^{3}$ \\
\hline
\end{tabular}

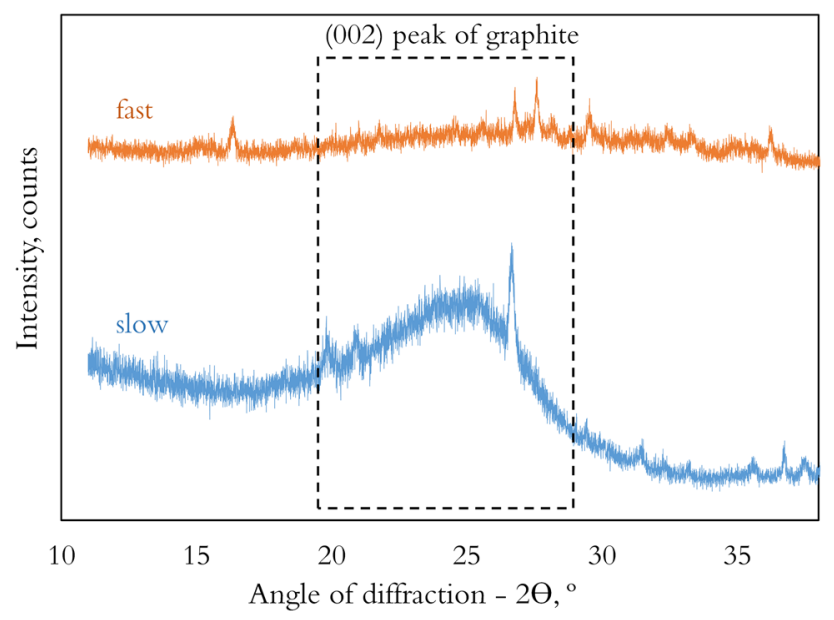

Fig. 16 XRD spectra of SRM chars produced at different heating rates

fast heating rate. In addition, the reactivity of SRM char produced at slow heating rate is lower than char made at a fast heating rate. The structure of carbon in the char is reported to play an important role in char gasification reactivity. It has been reported that char with more ordered crystalline structure has lower ordered gasification reactivity [28]. To examine the effect of devolatilization heating rate on the crystallinity of chars, X-ray diffraction technique was used.

Figure 16 shows the X-ray diffraction spectra of SRM char samples produced at slow and fast devolatilization rate. The position of the peak in the angle region of $27-29^{\circ}$, corresponds to the (002) peak of graphite, which is generally attributed to the stacking of the graphitic basal plans of chars [29]. The disordering of carbon crystalline structure results in the broadening of the (002) diffraction peak: the more disordering of carbon crystalline structure, the wider the diffraction peak of (002) [9]. The char produced at slow devolatilization heating rate shows more order in the structure, indicated by carbon (002) peak accompanied by an overlapping peak of silica, compared with the char produced at fast devolatilization heating rate, which explains the lower reactivity observed for the this char.

\section{Conclusion}

- The structure of SRM char and gasification of char are studied to gain a better understanding of its possible application in metallurgical processes. It was found that, although SRM produces a lower amount of char compared with coal char, the SRM char is more reactive than coal char; therefore, the gasification rate is higher.

- Proximate analysis of char shows a higher amount of ash present in SRM char. SRM char contains elements such as copper which has the potential to be extracted during the process; this indicates that utilizing this material in nonferrous metallurgy has the advantage of recycling of the inorganic component.

- SRM char has different physiochemical properties compared with coal char, which would result in different gasification behavior. In addition, the inorganic material present in both char samples has a catalytic effect on gasification rate and activation energy. The isothermal and nonisothermal gasification experiments with char samples show that the gasification of SRM char starts and finishes at a lower temperature compared with coal char. It was also observed that the calculated activation energy is lower for SRM char gasification. Furthermore, the higher gasification rate implies less chance of the unreacted char remaining in the process.

- The effects of devolatilization heating rate on the structure of char samples and their consequent gasification are studied. It was observed that, although the composition of char does not show considerable change, the morphology of char samples differs. Char samples produced at a faster heating rate, which is closer to devolatilization conditions in metallurgical processes, have more disordered crystalline carbon which leads to higher reactivity and, consequently, the gasification rate is higher.

Acknowledgments Financial supports from Boliden Commercial and the VINNOVA-supported Strategic innovation program for the Swedish mining and metal producing industry, SIP STRIM, are 
greatly appreciated. This study is within framework of CAMM, Center of Advanced Mining and Metallurgy.

Open Access This article is distributed under the terms of the Creative Commons Attribution 4.0 International License (http://crea tivecommons.org/licenses/by/4.0/), which permits unrestricted use, distribution, and reproduction in any medium, provided you give appropriate credit to the original author(s) and the source, provide a link to the Creative Commons license, and indicate if changes were made.

\section{References}

1. Ahmed N, Wenzel H, Hansen JB (2014) Characterization of shredder residues generated and deposited in Denmark. Waste Manag 34(7):1279-1288

2. Sahajwalla V, Zaharia M, Kongkarat S, Khanna R, SahaChaudhury N, O'Kane P (2009) Recycling plastics as a resource for electric arc furnace (EAF) steelmaking: combustion and structural transformations of metallurgical coke and plastic blends. Energy Fuels 24(1):379-391

3. Babich A, Senk D, Knepper M, Benkert S (2015) Conversion of injected waste plastics in blast furnace. Ironmak Steelmak 43(1):24-30

4. Mirabile D, Pistelli MI, Marchesini M, Falciani R, Chiappelli L (2002) Thermal valorisation of automobile shredder residue: injection in blast furnace. Waste Manag 22(8):841-851

5. Fink JK (1999) Pyrolysis and combustion of polymer wastes in combination with metallurgical processes and the cement industry. J Anal Appl Pyrolysis 51(1-2):239-252

6. Usachev A, Balasanov A, Lekherzak V, Romenets V (2000) Behaviour of coal in smelting reduction installation. Ironmak Steelmak 27(6):426-431

7. Richards G, Brimacombe J (1985) Kinetics of the zinc slagfuming process: part II. Mathematical model. Metall Trans B 16(3):529-540

8. Cockcroft S, Richards G, Brimacombe J (1988) Mathematical model of lead behaviour in the zinc slag fuming process. Can Metall Q 27(1):27-40

9. $\mathrm{Wu} \mathrm{H}(2015)$ The $\mathrm{CO}_{2}$ gasification kinetic study of WEEE plastic char derived from medium temperature pyrolysis. Energy Environ $\operatorname{Res} 5(1)$ :p82

10. Lin K, Chowdhury S, Wang Z (2010) Catalytic gasification of automotive shredder residues with hydrogen generation. J Power Sources 195(18):6016-6023

11. Brems A, Dewil R, Baeyens J, Zhang R (2013) Gasification of plastic waste as waste-to-energy or waste-to-syngas recovery route. Nat Sci 5:695-704

12. Narobe M, Golob J, Klinar D, Francetic V, Likozar B (2014) Cogasification of biomass and plastics: pyrolysis kinetics studies, experiments on $100 \mathrm{~kW}$ dual fluidized bed pilot plant and development of thermodynamic equilibrium model and balances. Bioresour Technol 162:21-29

13. Zevenhoven R, Karlsson M, Hupa M, Frankenhaeuser M (1997) Combustion and gasification properties of plastics particles. J Air Waste Manage Assoc 47(8):861-870

14. Beamish BB (1994) Proximate analysis of New Zealand and Australian coals by thermogravimetry. N Z J Geol Geophys 37(4):387-392

15. Yao Y, Liu D (2012) Comparison of low-field NMR and mercury intrusion porosimetry in characterizing pore size distributions of coals. Fuel 95:152-158

16. Barranco R, Rojas A, Barraza J, Lester E (2009) A new char combustion kinetic model 1. formulation. Fuel 88(12):2335-2339

17. Liu T, Fang Y, Wang Y (2008) An experimental investigation into the gasification reactivity of chars prepared at high temperatures. Fuel 87(4-5):460-466

18. Wang G, Zhang J, Shao J, Li K, Zuo H (2015) Investigation of non-isothermal and isothermal gasification process of coal char using different kinetic model. Int $\mathrm{J}$ Mining Sci Technol 25(1):15-21

19. Lahijani P, Zainal ZA, Mohamed AR (2012) Catalytic effect of iron species on $\mathrm{CO}_{2}$ gasification reactivity of oil palm shell char. Thermochim Acta 546:24-31

20. Sima-Ella E, Yuan G, Mays T (2005) A simple kinetic analysis to determine the intrinsic reactivity of coal chars. Fuel 84(14-15):1920-1925

21. He R, Sato J, Chen Q, Chen C (2002) Thermogravimetric analysis of char combustion. Combust Sci Technol 174(4):1-18

22. Saxena SC (1990) Devolatilization and combustion characteristics of coal particles. Prog Energy Combust Sci 16(1):55-94

23. Beyler CL, Hirschler MM (2002) Thermal decomposition of polymers. SFPE handbook of fire protection engineering 2 . Section 1, Chapter 7, pp 111-131

24. Lowell S, Shields JE, Thomas MA, Thommes M (2012) Characterization of porous solids and powders: surface area, pore size and density, vol 16. Springer, Berlin

25. Yu J, Lucas JA, Wall TF (2007) Formation of the structure of chars during devolatilization of pulverized coal and its thermoproperties: a review. Prog Energy Combust Sci 33(2):135-170

26. Asanuma M, Terada K, Inoguchi T, Takashima N (2013) Development of waste plastics pulverization for blast furnace injection. JFE Tech Rep 19:110

27. Umeki K, Moilanen A, Gómez-Barea A, Konttinen J (2012) A model of biomass char gasification describing the change in catalytic activity of ash. Chem Eng J 207-208:616-624

28. Huo W, Zhou Z, Chen X, Dai Z, Yu G (2014) Study on $\mathrm{CO}_{2}$ gasification reactivity and physical characteristics of biomass, petroleum coke and coal chars. Bioresour Technol 159:143-149

29. Lu L, Kong C, Sahajwalla V, Harris D (2002) Char structural ordering during pyrolysis and combustion and its influence on char reactivity. Fuel 81(9):1215-1225 